\title{
NOVAS OCORRÊNCIAS DE TUFAS NO VALE DO RIBEIRA (SP)
}

\section{NEW OCCURRENCES OF TUFA IN THE RIBEIRA RIVER VALLEY (SÃO PAULO STATE, BRAZIL)}

\author{
Bruna Bortoluzzi MIRAYA ${ }^{1}$; William SALLUN FILHO ${ }^{1,2}$; Ligia Maria Almeida Leite \\ RIBEIRO $^{1,3}$; Paulo Cesar BOGGIANI ${ }^{1}$; Helio SHIMADA ${ }^{2}$ \\ ${ }^{1}$ Instituto de Geociências, Universidade de São Paulo, São Paulo, SP. Emails: bruna.miraya@usp.br; boggiani@usp.br \\ ${ }^{2}$ Instituto Geológico, Secretária de Meio Ambiente do Estado de São Paulo. São Paulo SP. \\ Emails: wsallun@gmail.com; helio.shimada@gmail.com \\ ${ }^{3}$ CPRM - Companhia de Pesquisa de Recursos Minerais, SUREG-SP. São Paulo, SP. Email: ligia.ribeiro@cprm.gov.br
}

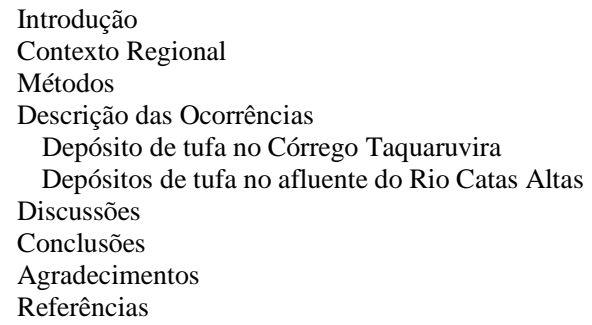

RESUMO - No Vale do Rio Ribeira, no Estado de São Paulo ocorrem depósitos de tufas, restritos a algumas drenagens desenvolvidas sobre áreas cársticas. Neste trabalho, são descritas duas novas ocorrências de tufas em afluentes do Rio Ribeira: os depósitos da Cachoeira de Taquaruvira, situada no Córrego Taquaruvira-Bombas (Iporanga, SP) e os depósitos de um afluente do rio Catas Altas (Ribeira, SP). Estas novas ocorrências de tufas, juntamente com as da Serra do André Lopes, são as únicas conhecidas na região e consideradas as de posição mais meridional dentre os depósitos descritos no Brasil. A primeira ocorrência está associada à área cárstica de Bombas (a montante) e apresenta depósitos em cachoeira já erodidos. A segunda está situada próxima a um pequeno corpo carbonático (não identificada como sendo uma área cárstica), e apresenta dois depósitos: o primeiro ativo, de tufas em cachoeira (que ocorre onde a drenagem possui maior gradiente hidráulico e recarga totalmente autogênica); e um outro inativo, de ruditos cimentados, mais a jusante (desenvolvido sobre uma superfície de baixa inclinação, com contribuição de recarga alogênica). Os depósitos de tufas descritos são caracterizados como represas e cachoeiras, formados em rios de vertente de bacia de drenagem com predomínio de recarga autogênica.

Palavras-chave: tufa; carbonatos continentais; fitoerma; Quaternário.

ABSTRACT - In the Ribeira River Valley (São Paulo State), tufa deposits occur in association with drainage features in the karst areas. In this paper, two new occurrences of tufa are described from the Ribeira River tributaries: the Taquaruvira waterfall deposits, situated on the Taquaruvira-Bombas Creek (Iporanga, São Paulo), and the Catas Altas River tributary deposits (Ribeira, São Paulo). These two new tufa occurrences, together with the Serra do André Lopes occurrences, are the only ones known in the region and are considered to be the most southern of all such deposits described in Brazil. The first occurrence is associated with the Bombas karst area (upstream) and comprises eroded cascade deposits. The second occurrence is situated near a small carbonate body (not identified as being in a karst area) and comprises two deposits: the first being an active, cascade tufa (which occurs where the drainage channel has a greater hydraulic gradient and completely autogenic recharge) and the other being composed of inactive, cemented rudites further downstream (which occurs on a lightly inclined surface with allogenic recharge). The deposits described are characterized as barrage and cascade deposits, laid down in hillside streams within a drainage basin where there is a predominance of autogenic recharge.

Keywords: tufa; continental carbonates; phytoherm; Quaternary.

\section{INTRODUÇÃO}

O estudo de tufas no Brasil tem crescido nos últimos anos em função de sua importância na interpretação paleoambiental e como possíveis análogos dos reservatórios de hidrocarboneto conhecidos como Pré-Sal, das bacias costeiras da margem continental brasileira. Nas áreas cársticas do Vale do Rio Ribeira, as tufas são menos expressivas do que em outras áreas cársticas do Brasil e do mundo, porém relevantes por serem os depósitos mais meridionais do Brasil e da América do Sul.

O sistema cárstico pode ser dividido em duas zonas, uma de erosão e uma de deposição (Ford \& Williams, 2007). Na zona de erosão a dissolução das rochas carstificáveis é o mecanismo para os outros processos, que ocorre ao longo de rotas subterrâneas, típicas do carste, alimentadas geralmente por águas meteóricas e também por água de circulação profunda (Ford \& Williams, 2007). A deposição de calcita no sistema cárstico se dá predominantemente na forma de travertinos e tufas na superfície e espeleotemas nas cavernas (Ford \& Williams, 2007).

Segundo Ford \& Pedley (1996) a tufa é o produto da precipitação de carbonatos em águas frias (não termais) e que tipicamente contém restos de micro- ou macrófitas, 
invertebrados e bactérias. Neste trabalho utilizaremos o termo tufa, em português, no lugar de "tufo calcário", "tufa calcária” ou travertino (Sallun Filho et al., 2009, Ford \& Pedley, 1996 e Pentecost, 2005).

Depósitos de tufa ativos e inativos têm sido descobertos no Brasil, dentre os quais alguns já foram descritos e estudados do ponto de vista sedimentológico, petrográfico e paleontológico, e até mesmo datados e posicionados cronologicamente.

Dentre os depósitos já descritos, destacamse as ocorrências: da Serra da Bodoquena (Almeida, 1965; Boggiani et al., 2002; Sallun Filho, 2005; Sallun Filho \& Karmann, 2007; Sallun Filho et al., 2009); da Serra das Araras (MT) (Almeida, 1943; Corrêa, 2006; Corrêa \& Auler, 2007; Corrêa et al., 2011); do sudoeste da Bacia Potiguar (Reyes, 2003; Reyes et al., 2003); da Paraíba e Ceará (Duarte \& Vasconcelos, 1980a, 1980b); do norte da Bahia (Auler \& Smart, 2001; Auler et al., 2004; Cristalli, 2006); do Rio de Janeiro (Ramos et al., 2005; Almeida, 2016); de Sergipe (Souza-Lima \& Farias, 2007) e do norte de Minas Gerais (Travassos \& Oliveira, 2016).

A presença de tufas é indicativa de condições geomorfológicas, hidrológicas e ambientais específicas, isto é, presença de vegetação sob clima temperado a quente, disponibilidade hídrica e alto gradiente hidráulico (Arenas-Abad et al. 2000).

Segundo Gradziński (2010) a presença de micro-organismos e valores altos do índice de saturação de calcita na água são os fatores primordiais que favorecem a precipitação e o crescimento de tufas. As altas concentrações de carbonato de cálcio dissolvido na água devido ao predomínio de recarga autogênica no sistema cárstico é também um fator importante para o desenvolvimento deste tipo de depósito (Arenas-Abad et al., 2000). Embora a vegetação seja importante para a deposição de tufa de forma geral é particularmente influente sob condições tropicais estacionalmente úmidas, fornecendo inclusive detritos de madeira para o rio (Carthew et al., 2003).

Almeida (2011) e Sallun Filho et al. (2012) descrevem e caracterizam alguns depósitos de tufa localizados na região da Serra do André Lopes, nos municípios de Eldorado e Barra do Turvo, associados ao carste desenvolvido em rochas carbonáticas do Meso a Neoproterozoico conhecidas como "Mármore da Tapagem", Supergrupo Açungui (Meso a Neoproterozoico, Campanha, 1991).

O presente trabalho, pela primeira vez, caracteriza em detalhe duas ocorrências de tufa previamente identificadas, porém não estudadas, na região de Iporanga e Ribeira, ambas na margem esquerda do Rio Ribeira (Figura 1).

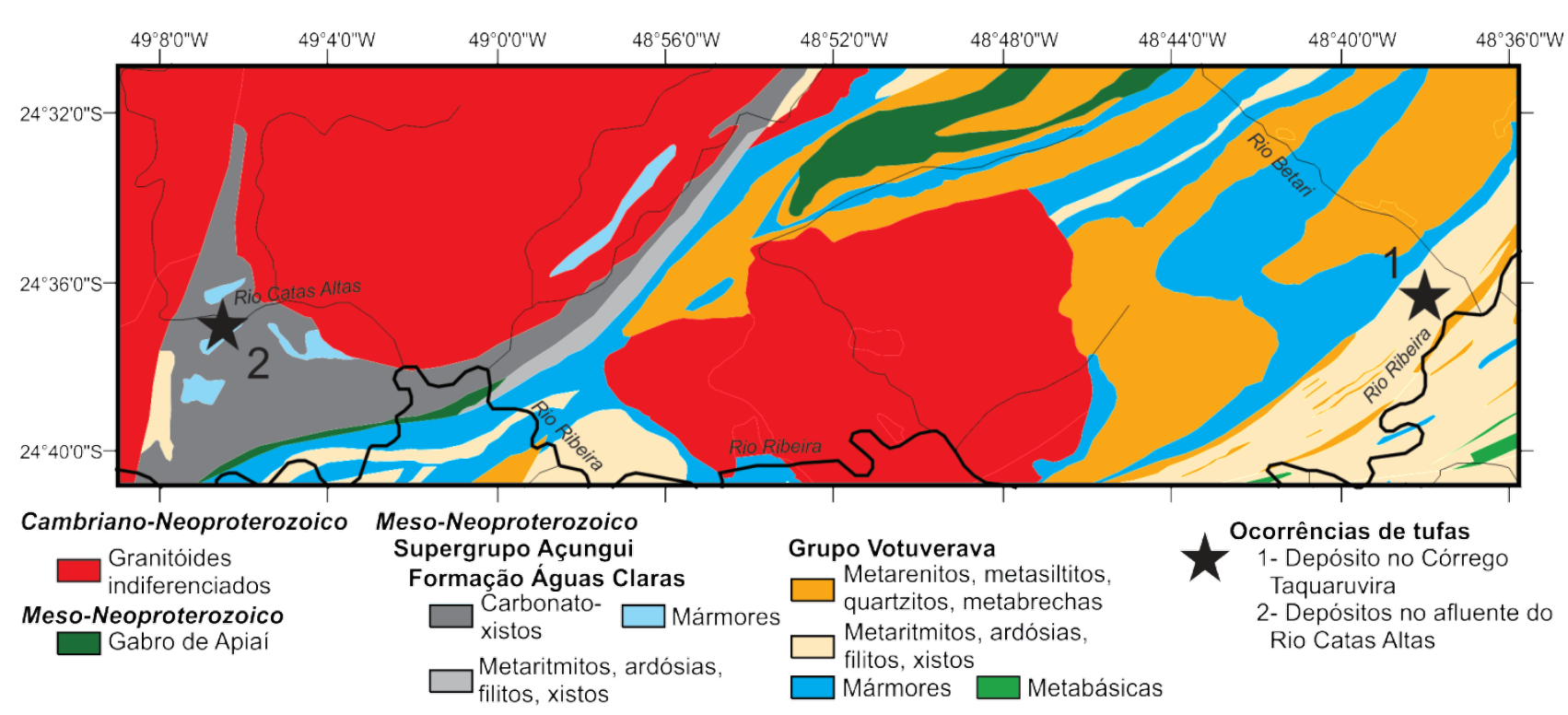

Figura 1 - Mapa geológico da área de estudo, com a localização das duas novas ocorrências de tufas (Base geológica modificada de Campanha, 2002). 
A primeira, no córrego Taquaruvira, a sul da cidade de Iporanga, foi identificada inicialmente através de fotos disponíveis na internet, que exibiam características morfológicas compatíveis com depósitos de tufas. Já a segunda ocorrência, do afluente à direita do Rio Catas Altas em Ribeira, foi descoberta pelo geólogo Hélio Shimada durante trabalhos de prospecção geoquímica no local (Gonzales et al., 1979). Os depósitos descritos neste trabalho, somados aos da Serra do André Lopes (Almeida, 2011 e Sallun Filho et al., 2012), constituem as únicas ocorrências descritas no Vale do Ribeira até o momento. Este trabalho tem como objetivo o mapeamento, a caracterização petrográfica e a classificação dos depósitos destas duas novas ocorrências de tufas, bem como interpretação sobre sua gênese.

\section{CONTEXTO REGIONAL}

A área de estudo situa-se no Terreno Apiaí, porção central da Província da Mantiqueira, limitado a sul pela Falha Lancinha, que o separa do Terreno Curitiba. Possui embasamento Paleoproterozoico composto por ortognaisses migmatíticos-miloníticos, de grande complexidade geológica, devido à superposição de eventos tectônicos distintos (Faleiros, 2008). Compreende rochas supracrustais metamorfizadas da Faixa Dobrada de Apiaí, designadas como Supergrupo Açungui, além de rochas resultantes de extenso magmatismo granítico brasiliano (Campanha, 2002).

O primeiro depósito de tufa, de Iporanga, ocorre sobre as rochas siliciclásticas da Formação Iporanga, com cerca de $580 \mathrm{Ma}$ (Campanha et al., 2008), constituída essencialmente por metarritmitos, ardósias e filitos (Campanha, 2002). Rochas metacalcárias do Grupo Lajeado (Faleiros et al., 2012), a montante do córrego Taquaruvira, são a fonte do carbonato.

Já o segundo depósito, de Ribeira, está associado a rochas da Formação Água Clara, que tem idades estimadas entre 1600 e 1450 Ma (Siga Junior et al., 2011), predominantemente de carbonato-xistos, mármores, quartzitos e micaxistos (Campanha, 2002).

De forma geral, os corpos carbonáticos do
Grupo Lajeado na região são áreas rebaixadas em relação às unidades subjacentes (mais antigas), compostas por rochas nãocarbonáticas do Supergrupo Açungui, acarretando sistemas cársticos de recarga mista e injeção alogênica (Karmann \& Sanchez, 1979, 1986; Karmann \& Ferrari, 2002). Situações distintas dessa são observadas nos corpos carbonáticos da Serra do André Lopes (Mármore da Tapagem) (Sallun Filho et al., 2012) e da Formação Água Clara.

De acordo com a macrocompartimetação do relevo de Ross \& Moroz (1997), a área de estudos faz parte da unidade morfoestrutural do Planalto Atlântico. Esta unidade é dividida em unidades menores, das quais as duas ocorrências pertencem ao Planalto Ribeira/Turvo. Segundo a descrição de Ross \& Moroz (1997), o Planalto Ribeira/Turvo apresenta cotas altimétricas entre 700-900 m ou maiores que $900 \mathrm{~m}$, com declividades dominantes de $20 \%$ a $30 \%$, formas de topos aguçados e grau de entalhamento dos vales de fraco a forte.

A região do Vale do Ribeira tem clima subtropical úmido com médias anuais de chuva em torno de 1300-1500 mm, sem estação seca e temperatura média de $19-20{ }^{\circ} \mathrm{C}$ (Alvares et al., 2013).

\section{MÉTODOS}

Nos trabalhos de campo, desenvolvidos segundo os métodos usuais, foi possível localizar as ocorrências com precisão, realizar medidas da extensão dos depósitos, verificar variações laterais e verticais das tufas, proceder a documentação fotográfica e coletar amostras. Além dos pontos-alvo, foram percorridos trechos das respectivas drenagens para avaliar a presença de outros depósitos. As amostras coletadas foram enviadas para a confecção de lâminas delgadas, as quais foram analisadas ao microscópio óptico Olympus (BXP 50), para a descrição da textura e da mineralogia, e estimativa da porosidade.

Foram levantadas informações sobre a rede de drenagem e a geologia regional, reunidas através do software ARCGIS 10.2.1. Utilizouse a carta geológica 1:50.000 de Campanha (2002) e Faleiros et al. (2012) como referências para as unidades geológicas regionais.

Curvas de nível com intervalo de $5 \mathrm{~m}$ e perfis topográficos das drenagens foram 
gerados através do software Global Mapper, com base nos dados de elevação SRTM. Os gradientes hidráulicos foram definidos através dos perfis topográficos, calculando-se a razão entre a variação altimétrica do nível do rio e a distância horizontal percorrida. As áreas de recarga autogênicas e alogênicas foram calculadas pela razão entre a área de todas as bacias de drenagem sobre as rochas carbonáticas e não-carbonáticas, respectivamente, e a área total da bacia, com base nos mapas geológicos utilizados e as drenagens das folhas topográficas 1:10.000 do Instituto Geográfico e Cartográfico.

\section{DESCRIÇÃO DAS OCORRÊNCIAS}

\section{Depósito de tufa no Córrego Taquaruvira}

A primeira das duas novas ocorrências de tufas no Vale do Rio Ribeira, o depósito no Córrego Taquaruvira, situa-se na bacia Bombas-Taquaruvira, associado à área de carste poligonal de Bombas, que escoa para vales fluviais a jusante.

O Córrego Taquaruvira escoa sobre as rochas carbonáticas do Grupo Lajeado, a montante da tufa estudada, em direção ao Rio Ribeira, onde é chamado de Córrego Bombas. Esta bacia de drenagem (Bombas-Taquaruvira) está associada a uma área cárstica bastante desenvolvida, composta por uma superfície rebaixada em relação às rochas não carbonáticas, o que condiciona um sistema de recarga misto (Karmann, 1994). As drenagens autogênicas são formadas a partir da infiltração de água pluvial no planalto, em pontos de absorção localizados no interior de depressões fechadas, caracterizando um carste poligonal. A recarga superficial alogênica é proveniente da serra da Anta Gorda e da serra do Sem Fim (Genthner et al., 2003).

A área de Bombas localiza-se em um anticlinal de flanco invertido. Há uma falha no contato sudeste do corpo carbonático, onde o Rio Bombas está encaixado em grande parte de seu curso.

As águas superficiais, bem como as águas do sistema cárstico subterrâneo, reaparecem na ressurgência de Bombas (Genthner et al., 2003) e seguem para o Rio Ribeira através do Córrego Taquaruvira (Figura 2). A área cárstica relativa à bacia do Córrego Bombas tem predomínio de recarga autogênica (71\%). O Córrego Bombas possui gradiente hidráulico de 0,1 a 0,26 no seu alto curso, e de 0,03 a 0,007 , no médio curso, próximo ao contato com as rochas não carbonáticas.

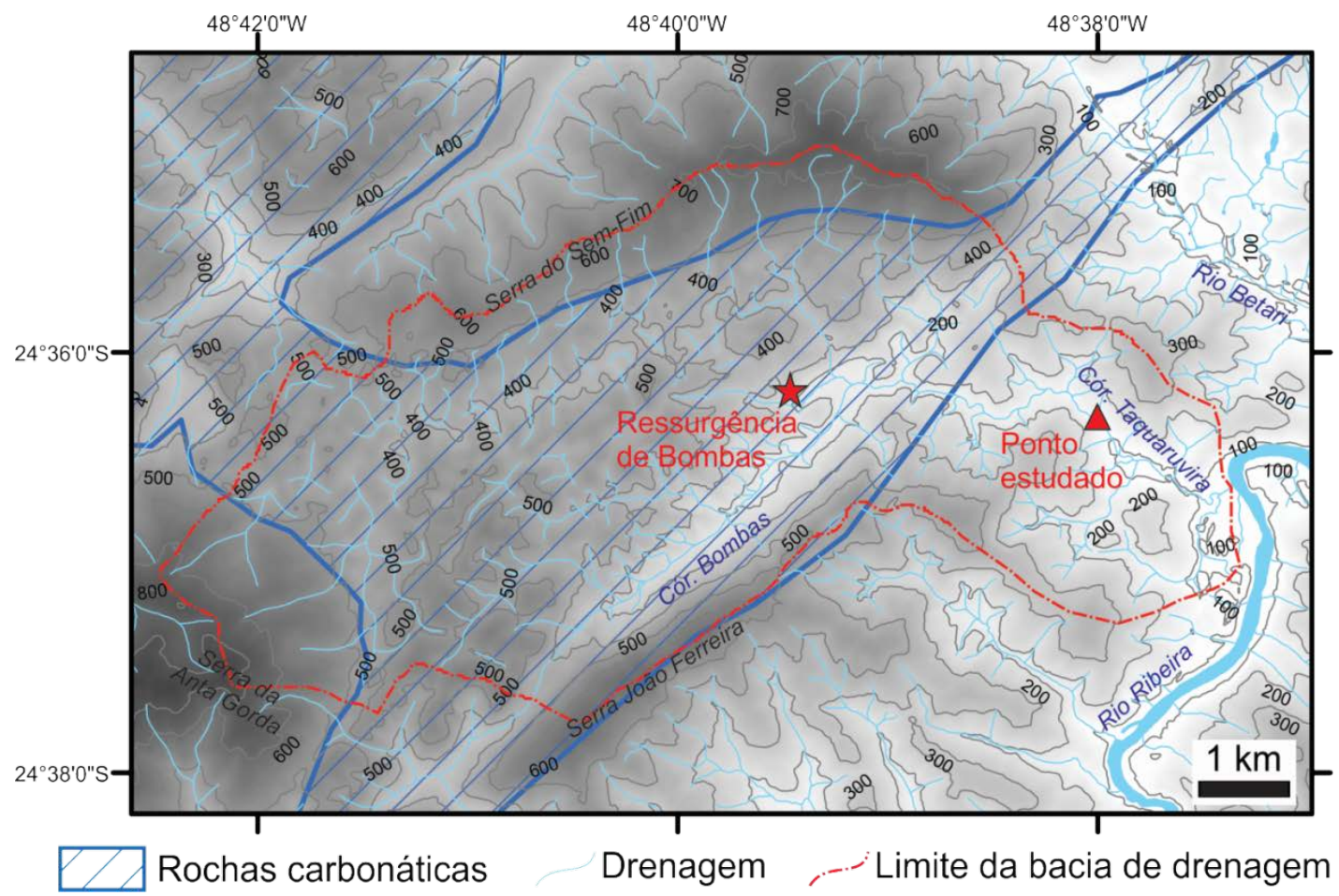

Figura 2 - Mapa mostrando a localização do depósito do Córrego Taquaruvira e da área cárstica de Bombas (limites do metacalcário segundo Campanha, 2002, drenagens extraídas de folhas topográficas 1:10.000 do Instituto Geográfico e Cartográfico) e localização da ressurgência de Bombas segundo Genthner et al. (2003). 
Os depósitos de tufa ocorrem onde o Córrego Taquaruvira escoa sobre os filitos da Formação Iporanga, a jusante dos metacalcários. Nesta porção a drenagem possui gradiente hidráulico relativamente baixo (entre 0,08 a 0,03). O depósito localiza-se em uma cachoeira, que em escala local, representa maior gradiente hidráulico. O principal depósito está localizado na Cachoeira Taquaruvira (Figura
3, coordenadas $24^{\circ} 36^{\prime} 19^{\prime \prime S} / 48^{\circ} 38^{\prime} 00^{\prime \prime} \mathrm{W}$ ) e neste ponto encontra-se inativo e parcialmente erodido. A tufa ocorre com o formato de concha, com convexidade para cima, formando cortinas de carbonato, sendo caracterizado como Depósito de Cachoeira (Pedley, 1990) ou como Cascata (Pentecost, 2005). A seção vertical resultante da erosão permite observar sua estrutura interna laminada.
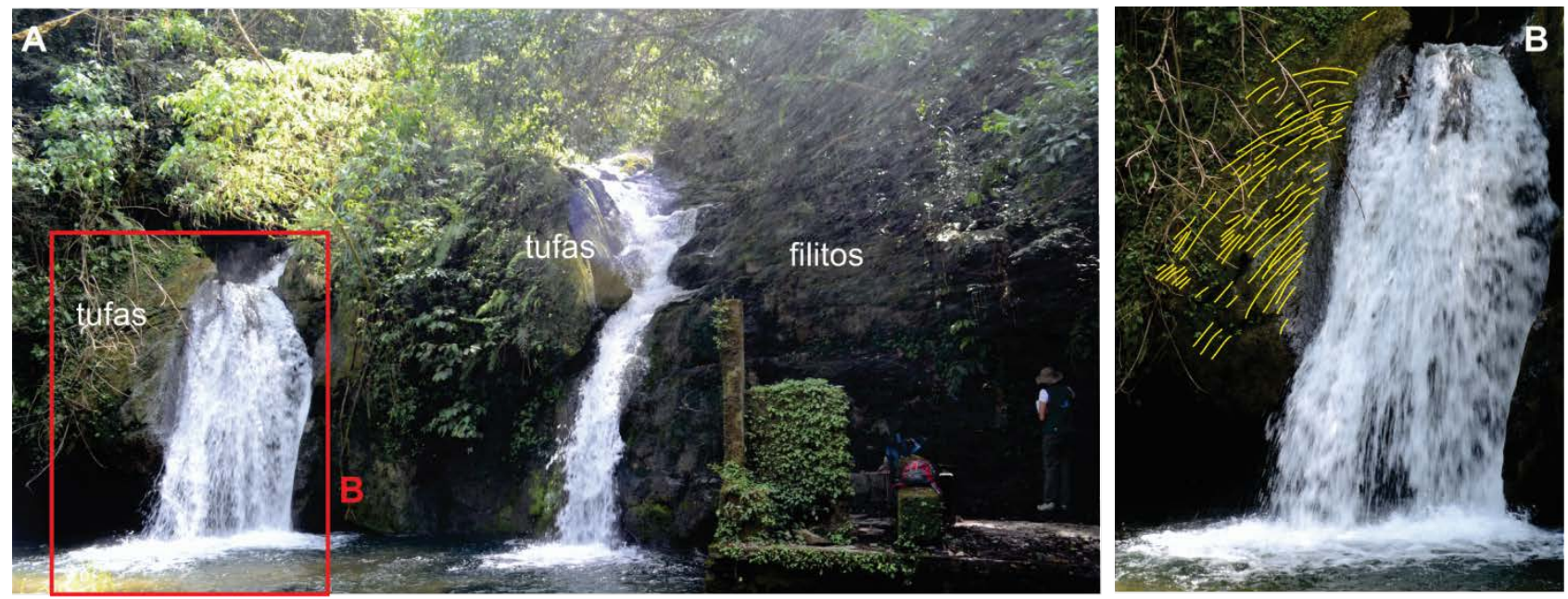

Figura 3 - A- Vista geral da Cachoeira do Taquaruvira, mostrando depósitos de tufa; B- Detalhe do depósito erodido, evidenciando a laminação interna.

Observaram-se resquícios de um antigo depósito inativo, parcialmente erodido, que consiste em matacões de tufas dentro da calha atual do rio, tanto acima quanto abaixo da cachoeira. No leito da drenagem, há deposição ativa de uma crosta de carbonato pouco espessa (poucos milímetros), de coloração cinzaesverdeada (Figura 4-A), onde a água flui continuamente, que por vezes apresenta laminação ondulada, em forma dômica a pseudo-colunar, com poros preenchidos por sedimentos terrígenos (Figura 4-B).
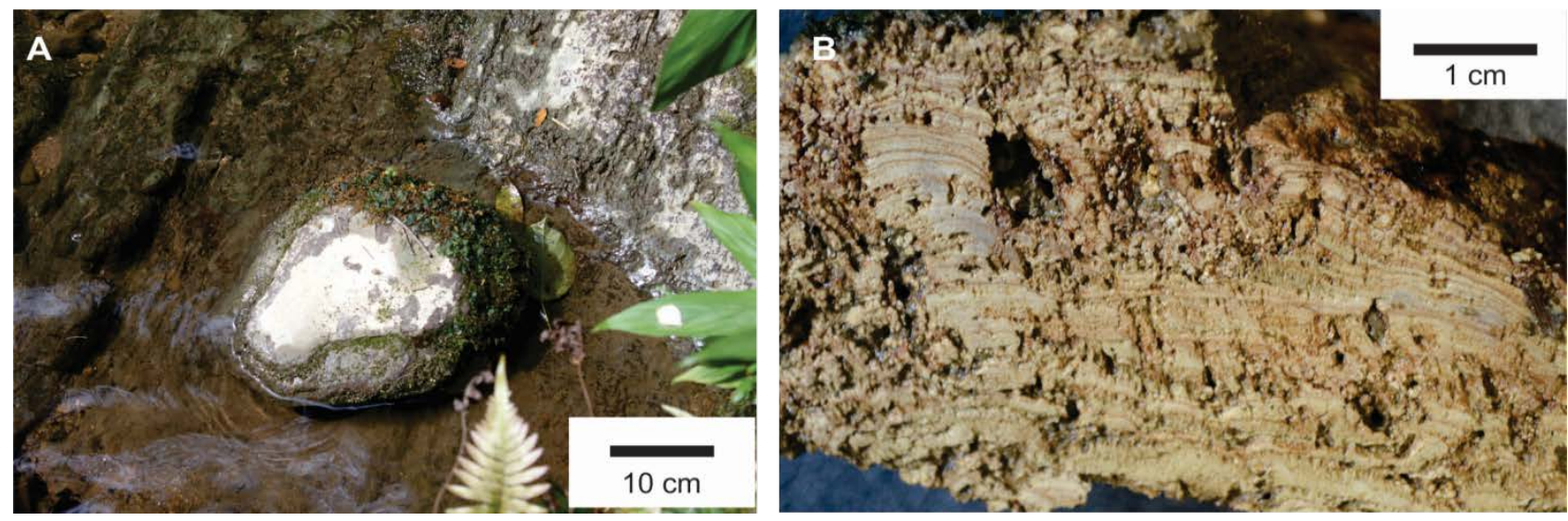

Figura 4 - A) Local acima da Cachoeira do Taquaruvira com deposição ativa de crosta de carbonato pouco espessa em bloco no leito do rio; B) Amostra de mão do depósito da Cachoeira do Taquaruvira exibindo laminação ondulada, em forma dômica, pseudo-colunar, e poros preenchidos por sedimentos terrígenos.

O depósito parcialmente erodido de tufas da Cachoeira do Taquaruvira possui laminação submilimétrica ondulada, de forma dômica (Figura 5-A), com inclinação acompanhando a morfologia do depósito, bastante porosa e friável. Possui restos vegetais incrustados, e parte dos poros preenchidos por sedimentos terrígenos (principalmente as amostras coletadas dos matacões), com predomínio de cristais angulosos de quartzo, e cristais tabulares de muscovita (Figura 5-C). 

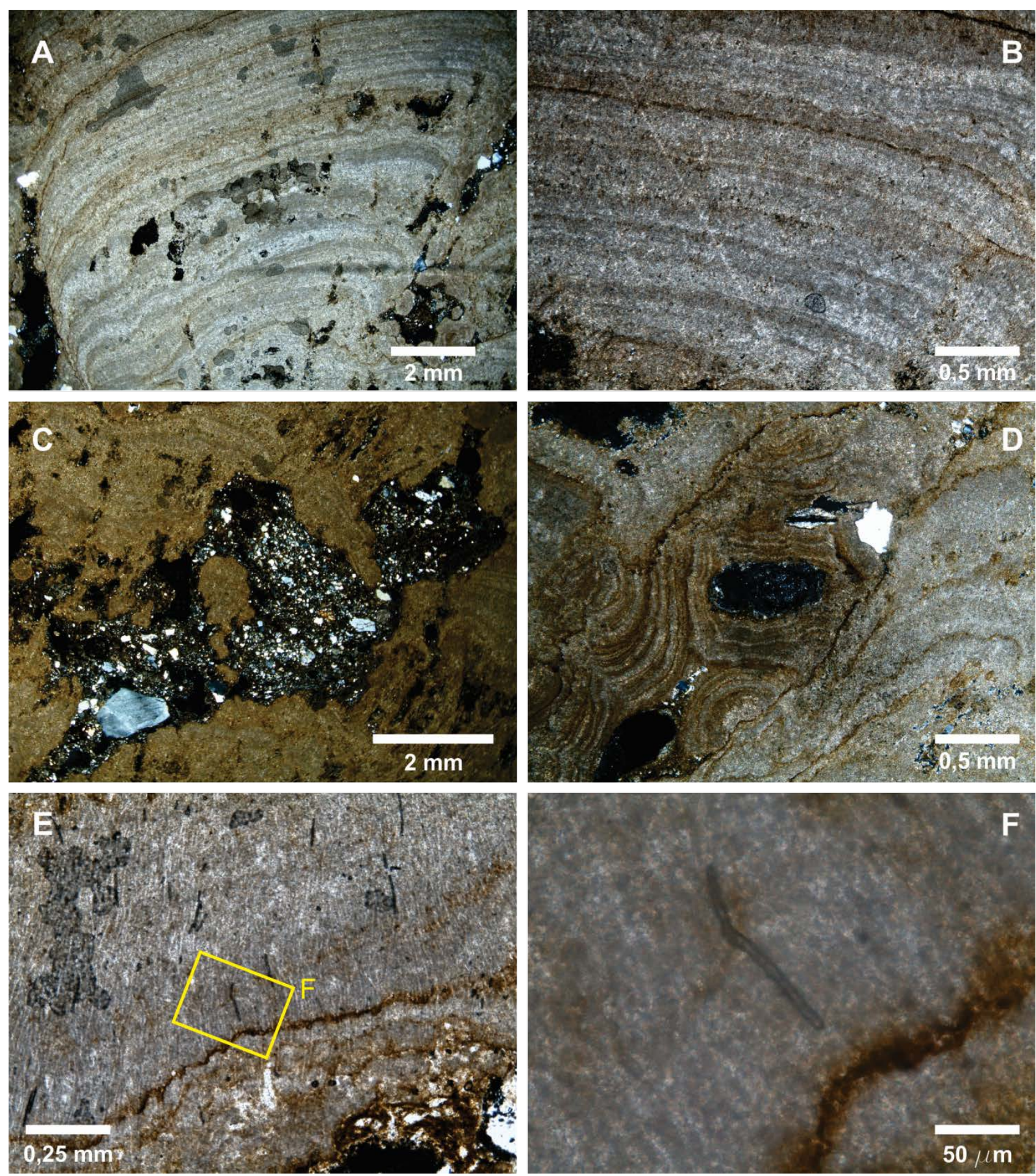

Figura 5 - Fotomicrografias do depósito no Córrego Taquaruvira (polarizadores cruzados): A- Laminação ondulada, em forma dômica, com poros interlamelares, poros cortando a laminação e nos limites do edifício; B- Detalhe da laminação fina, micrítica, com alternâncias de camadas claras e escuras; C- Sedimentos terrígenos preenchendo porosidade; DCrescimento secundário de tufa, em estrutura concêntrica ao redor de poros; E- Laminação fina, micrítica, com filamentos de cianobactérias perpendiculares à laminação (segundo direção de crescimento); F- Detalhe dos filamentos preservados de cianobactérias perpendiculares à laminação.

Sob microscópio petrográfico é possível observar uma alternância entre lâminas micríticas claras e escuras (Figura 5-B), compondo uma laminação irregular, em forma dômica, que lembra uma laminação microbial, com direções de crescimento ligeiramente divergentes e truncadas, o que pode representar uma mudança relativa da intensidade do fluxo d'água sobre o depósito. Há cimentação secundária por óxidos principalmente ao redor de poros, preenchendo-os parcialmente, e nos contatos entre diferentes direções de laminação, o que as ressalta. A rocha possui aproximadamente $25 \%$ de porosidade, com poros desde 
arredondados a ovalados a irregulares, que cortam a laminação, ou se alongam segundo a mesma, e poros aciculares, menores, alongados na direção perpendicular à laminação (ou seja, paralelos à direção de crescimento) também são comuns. Os poros arredondados a ovalados são, possivelmente, decorrentes de restos vegetais, que foram incrustados, e, após sua decomposição, sua forma ficou preservada. Já os poros alongados foram interpretados como vazios associados ao crescimento bioinduzido da tufa (Flügel, 2004). Preenchendo parcialmente os poros maiores, ocorrem estruturas concêntricas, indicando crescimento secundário, que se deve à percolação de água nos poros (Figura 5-D).

Filamentos de bactérias, tubulares e incrustados, ocorrem nos níveis laminados (Figura 5-E e F), e sua morfologia, quando comparada com registros da literatura, sugere serem do gênero Phormidium (Freytet \& Verrecchia, 1998).

\section{Depósitos de tufa no afluente do Rio Catas Altas}

A segunda ocorrência situa-se próximo a um pequeno corpo carbonático, sem informações sobre a presença de carste.

$\mathrm{O}$ afluente do rio Catas Altas e as drenagens secundárias associadas correm na maior parte de seu percurso sobre rochas carbonáticas da Formação Água Clara, que no local é composta por metarenitos carbonáticos e rochas calciossilicáticas (Gonzales et al., 1979; Weber et al., 2004). Somente parte das drenagens a sudeste possui recarga alogênica, sendo a recarga autogênica responsável por $87 \%$ da recarga da bacia.

Nesta drenagem observaram-se dois pontos de ocorrência de tufas (Figura 6, coordenadas $24^{\circ} 36^{\prime} 47^{\prime \prime S} / 49^{\circ} 06^{\prime} 22^{\prime \prime} \mathrm{W}$ e 2436'59"S/ 4906'26"W). O gradiente hidráulico varia de 0,23 no seu alto curso, para 0,3 no médio curso (depósito 1) e 0,13 no baixo curso (depósito 2).

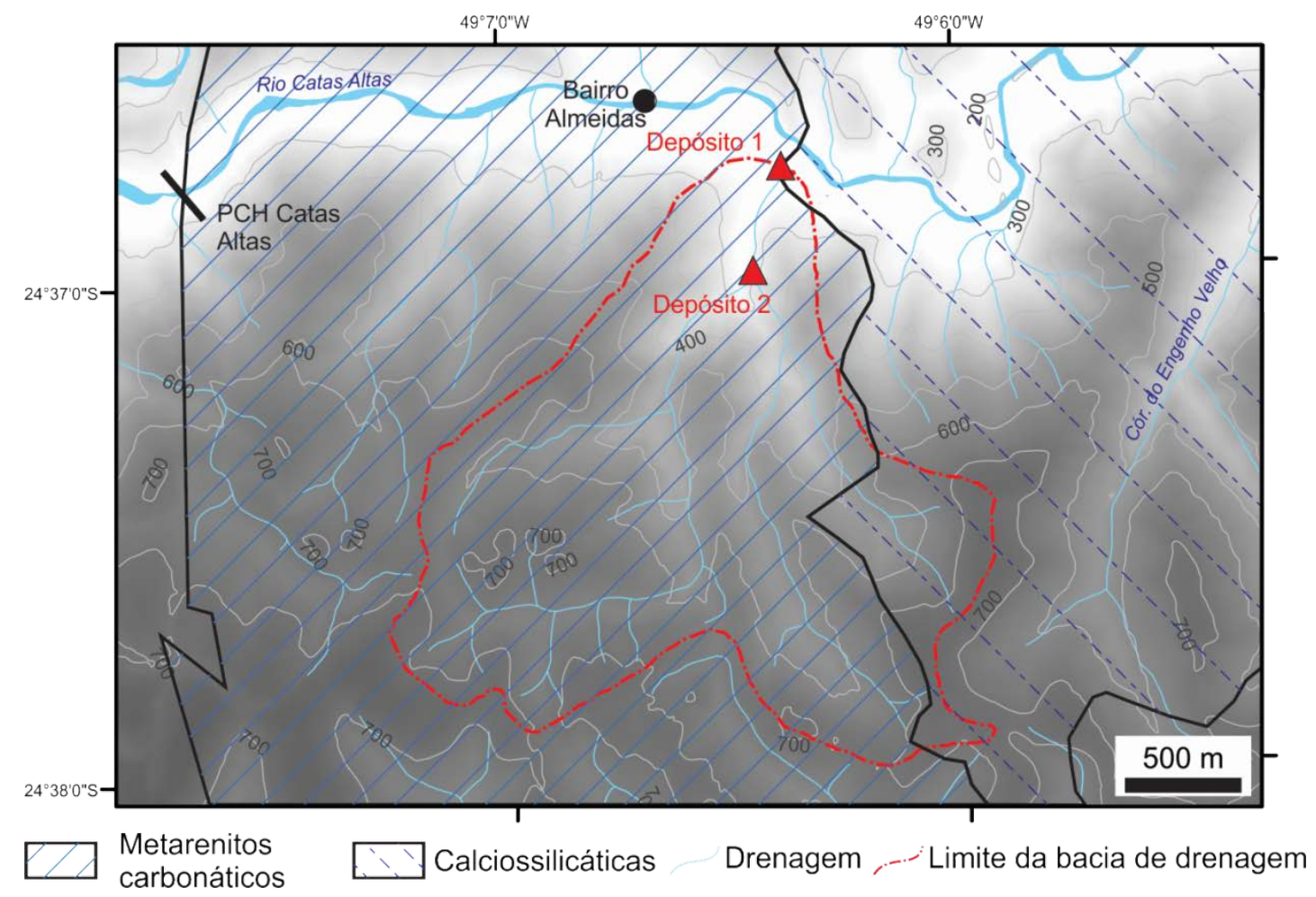

Figura 6: Mapa de localização dos depósitos na bacia de drenagem do afluente do rio Catas Altas (base geológica modificada de Gonzales et al., 1979, e drenagens extraída de folhas topográficas 1:10.000 do Instituto Geográfico e Cartográfico).

O depósito 1, na porção mais jusante da drenagem, ocorre sobre uma superfície de baixa inclinação e possui contribuição de recarga alogênica. Neste ponto observou-se um matacão ex situ (Figura 7-A), composto de clastos líticos angulosos, não carbonáticos, com a granulação variando de grânulo a seixo, cimentados por tufa laminada, friável e porosa (Figura 8). Esta litologia representa uma variação irregular de fácies alóctone e autóctone, gradando para uma tufa pouco porosa e com laminação bem marcada para o topo (Figura 7-B e Figura 9-A). A fácies autóctone apresenta laminação milimétrica, com 
alternância de lâminas de cor clara e escura, localmente com forma dômica. É possível observar a alternância de duas porções distintas dentro dessa fácies: uma pouco porosa (8\% da rocha), com laminação bem marcada; e outra bastante porosa (30\% da rocha) e não laminada.
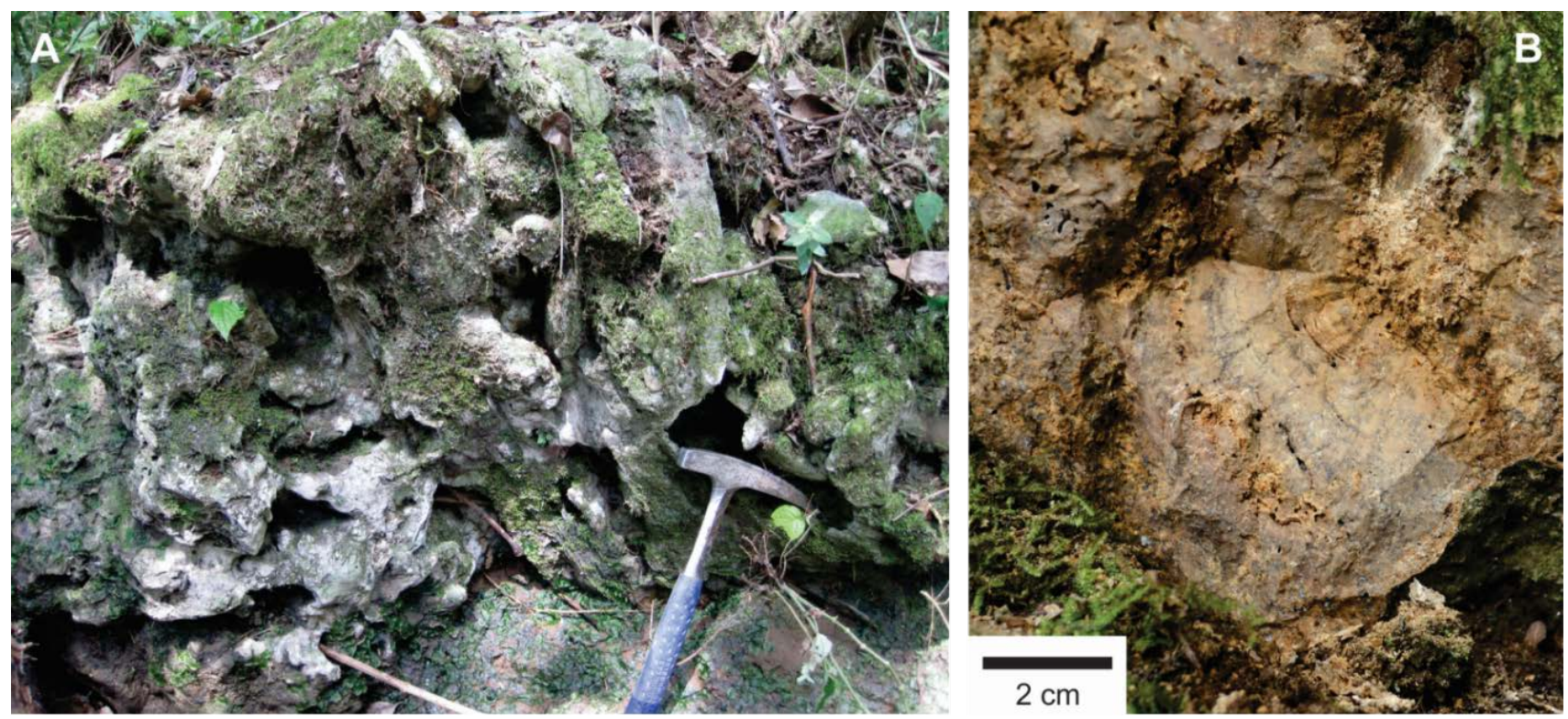

Figura 7 - Afluente do Rio Catas Altas, depósito 1: A- Matacão ex situ de ruditos com clastos líticos cimentados por tufa; B- Tufa com fácies laminada e maciça, alternada com fácies não laminada e porosa, em matacão ex situ.

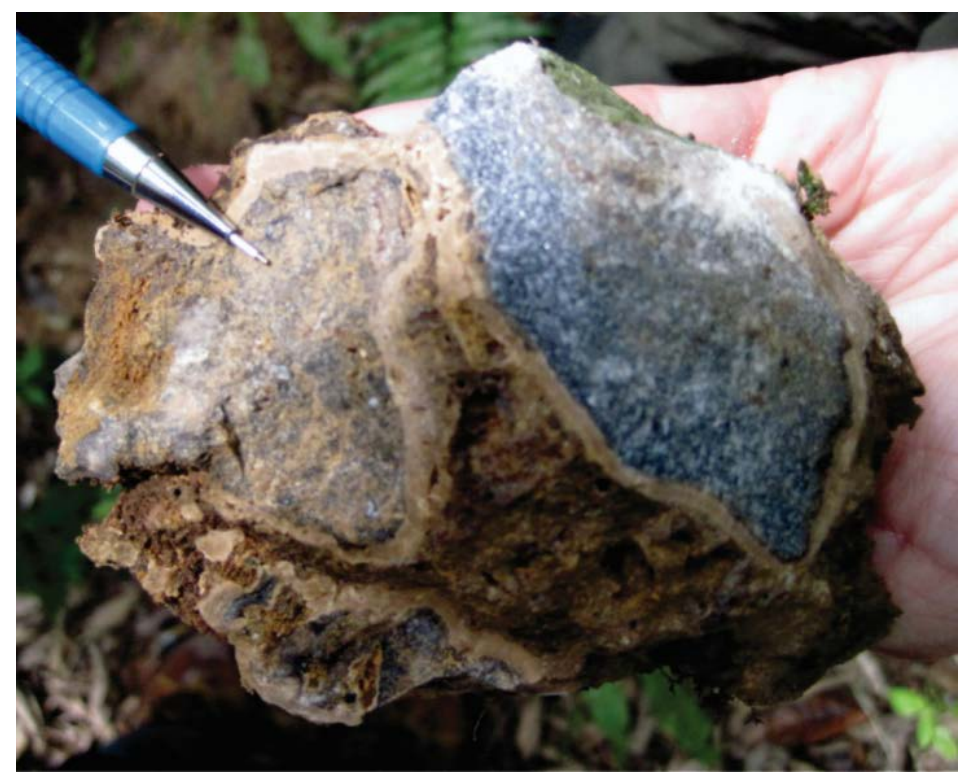

Figura 8 - Afluente do Rio Catas Altas, depósito 1: Amostra de mão de rudito (clastos líticos) cimentado por tufas.

Em análise petrográfica de lâmina delgada foi possível observar que a porção menos porosa possui alternância de lâminas micríticas e microesparíticas, sendo a última subordinada. A laminação, em geral, é plana, mas localmente se torna ondulada, lembrando laminação microbiana lateralmente contínua (Figura 9-B). Ocorrem poros arredondados a ovalados, que interrompem a laminação, ou se alongam segundo a mesma. Contudo poros aciculares, menores, alongados na direção perpendicular à laminação (ou seja, paralelos à direção de crescimento) são os mais comuns (Figura 9-C), podendo refletir a organização dos filamentos microbianos. Os poros arredondados podem representar moldes de restos vegetais; os alongados paralelos à laminação foram interpretados como porosidade fenestral, que pode ser originada pela desintegração de matéria orgânica depositada junto com a tufa, ou por dissecação e separação das lâminas (Hardie, 1977). 

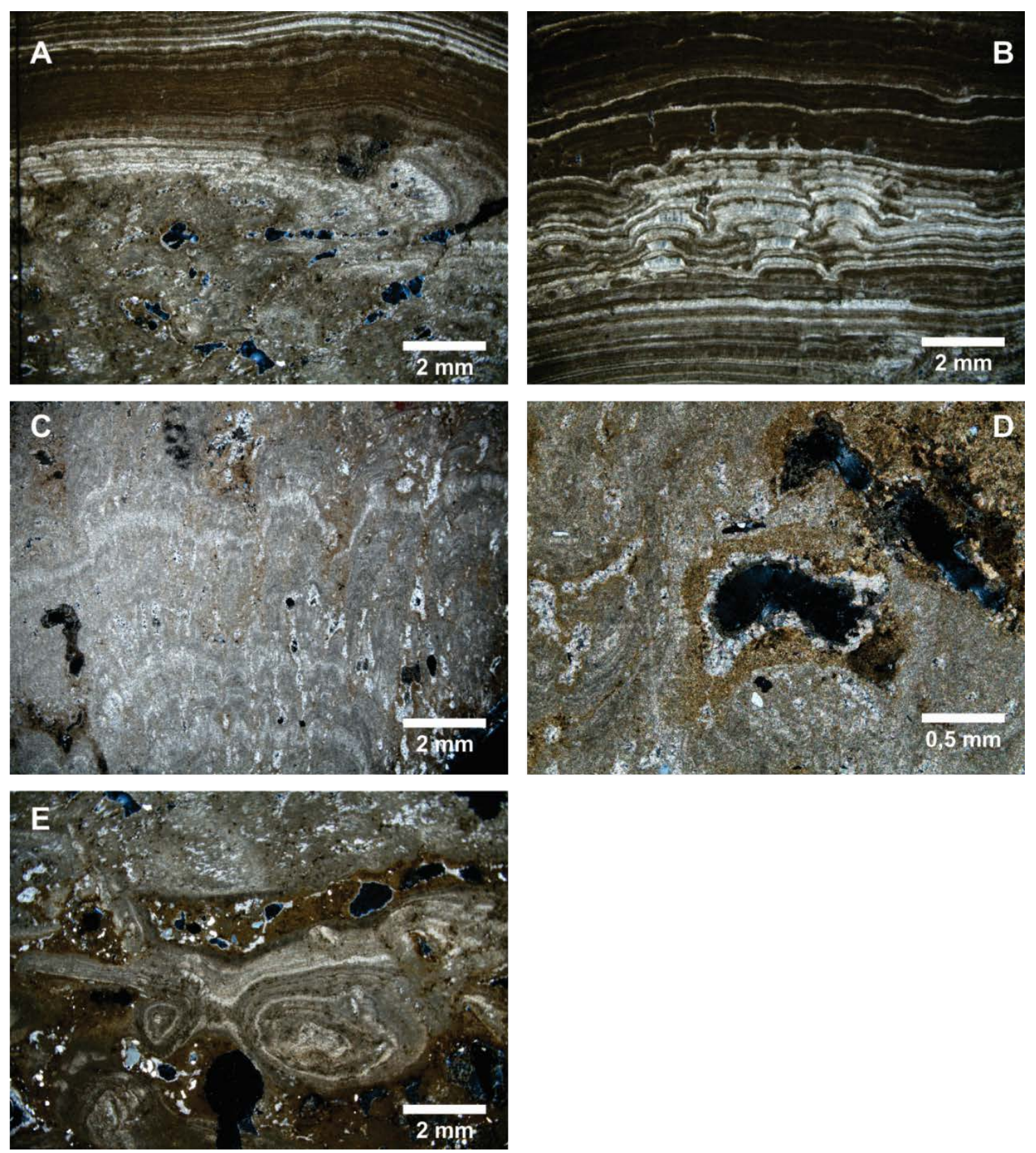

Figura 9 - Fotomicrografias dos matacões ex situ do depósito 1 do afluente do Rio Catas Altas (polarizadores cruzados): A- Contato entre zona muito porosa e maciça, e zona pouco porosa com laminação bem marcada evidenciando mudanças no ambiente deposicional; B- Intercalação entre laminação planar e laminação microbiana lateralmente contínua; C- Laminação similar a estromatólitos micropseudocolunares com poros alongados entre os domos; D- Poros totalmente preenchidos por microesparito, ou parcialmente preenchidos por calcita esparítica; EPisólitos e clastos terrígenos (quartzo), cimentados por micrito rico em óxidos.

Os poros aciculares foram interpretados como vazios associados ao crescimento bioinduzido da tufa. A porção mais porosa possui laminação bem marcada em porções restritas, de forma dômica, lembrando estromatólitos micropseudocolunares (Figura 9B), com grandes poros, alongados segundo a direção de crescimento, limitando os domos. Tanto esses poros, quanto os arredondados, em grande parte, estão totalmente preenchidos por microesparito secundário. Os poros maiores estão parcialmente preenchidos por calcita espática (Figura 9-D). Óxidos ocorrem preenchendo poros, e como cimento secundário ao redor dos mesmos. Há uma grande quantidade de material terrígeno (grãos angulosos a subangulosos de quartzo) nos poros não cimentados.

A porção autóctone se intercala de maneira irregular com porções alóctones submilimétricas, compostas por pisólitos, cimentados em menisco, o que indica cimentação em condições subaéreas; observam-se também grãos subangulosos de quartzo cimentados aos 
pisólitos por um cimento micrítico mais rico em óxido (Figura 9-E).

Em macroescala, a fácies alóctone é constituída por clastos líticos não carbonáticos. Essa mudança de fácies indica mudança significativa no grau de energia relacionado ao ambiente deposicional. Nas fases de maior energia houve maior contribuição de recarga alóctone, depositando material terrígeno e intraclastos, cimentados por carbonato impuro. $\mathrm{Na}$ gradação para fases de menor energia, ocorria maior contribuição de recarga autogênica. Estas mudanças de energia resultaram na deposição de tufa com laminação bem marcada. Esse depósito é classificado como rudito com a superfície cimentada, segundo classificação de Pentecost (2005), intercalado com depósitos autóctones de tufa fitoermal (Flügel, 2004).

No segundo ponto (depósito 2), cerca de 500 $\mathrm{m}$ do primeiro seguindo para montante na drenagem, existem dois depósitos ativos de tufas, distantes poucos metros um do outro. São duas cachoeiras, uma maior com aproximadamente $10 \mathrm{~m}$ de altura, e a outra menor com cerca de 7 metros, localizada mais a montante em relação à primeira (Figura 10-A). Nessa porção, a drenagem possui gradiente hidráulico maior, e a recarga é totalmente autogênica.
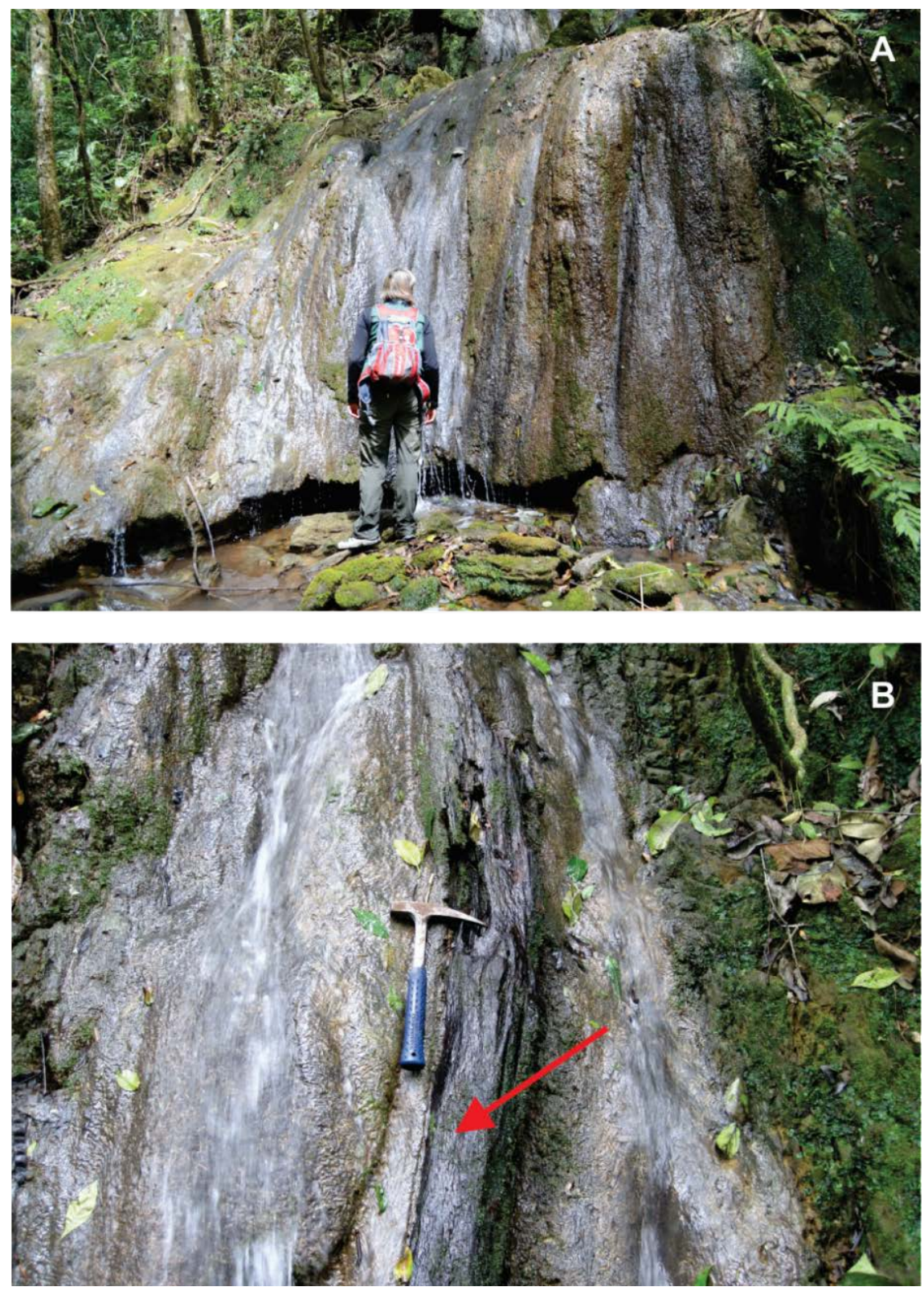

Figura 10 - Afluente do Rio Catas Altas, depósito 2: A- Depósito ativo de tufa em cachoeira, com morfologia convexa e alta inclinação; B- Detalhe da tufa em cachoeira com presença de restos vegetais incrustados, incluindo fragmentos menores como folhas e raízes, até maiores como eixos caulinares e troncos (exemplificado por fragmento com tonalidade mais escura, indicado pela seta). 
As tufas das duas localidades possuem a forma característica de concha, com a porção convexa voltada para cima, caracterizando um depósito do tipo cachoeira (Pedley, 1990), ou do tipo cascata (Pentecost, 2005). A deposição é ativa e ocorre principalmente onde há fluxo de água turbulento. Contudo, também há deposição por gotejamento em setores da cachoeira com menor fluxo. Foram observados restos vegetais em processo de incrustação por carbonato (Figura 10-B). Observam-se pequenas variações em relação à dureza e à porosidade das tufas em diferentes porções do mesmo depósito, mas as tufas do depósito 2 são mais porosas e friáveis que as encontradas no depósito 1, e possuem porções com aspecto maciço e outras com laminação mal definida (Figura 11).

Em análise petrográfica de seção delgada foi possível observar a alternância de lâminas micríticas mais claras e mais escuras. Contudo a tonalidade entre as lâminas é bastante próxima, tornando muitas vezes difícil distingui-las (Figura 12-A).
A laminação é plano-paralela, levemente ondulada, localmente com feições dômicas. A rocha é bastante porosa, apresentando poros que são moldes de restos de vegetais (Figura 12-B). Há poros alongados segundo a direção de crescimento. Esta porosidade foi interpretada como associada ao crescimento bioinduzido da tufa.

Observam-se também poros alongados paralelos à laminação, interpretados como porosidade fenestral, que podem ser originados pela decomposição de matéria orgânica depositada durante o processo de formação da tufa, ou por dissecação e separação das lâminas (Hardie, 1977). Parte dos poros está preenchida por microesparito e óxidos, sendo que em alguns poros ocorrem grãos de quartzo. A porosidade aumenta em direção ao topo.

Nesta amostra foi observada grande quantidade de filamentos de cianobactérias, aparentemente incrustados por carbonato e orientados segundo a direção de crescimento (Figura 12-C e D).

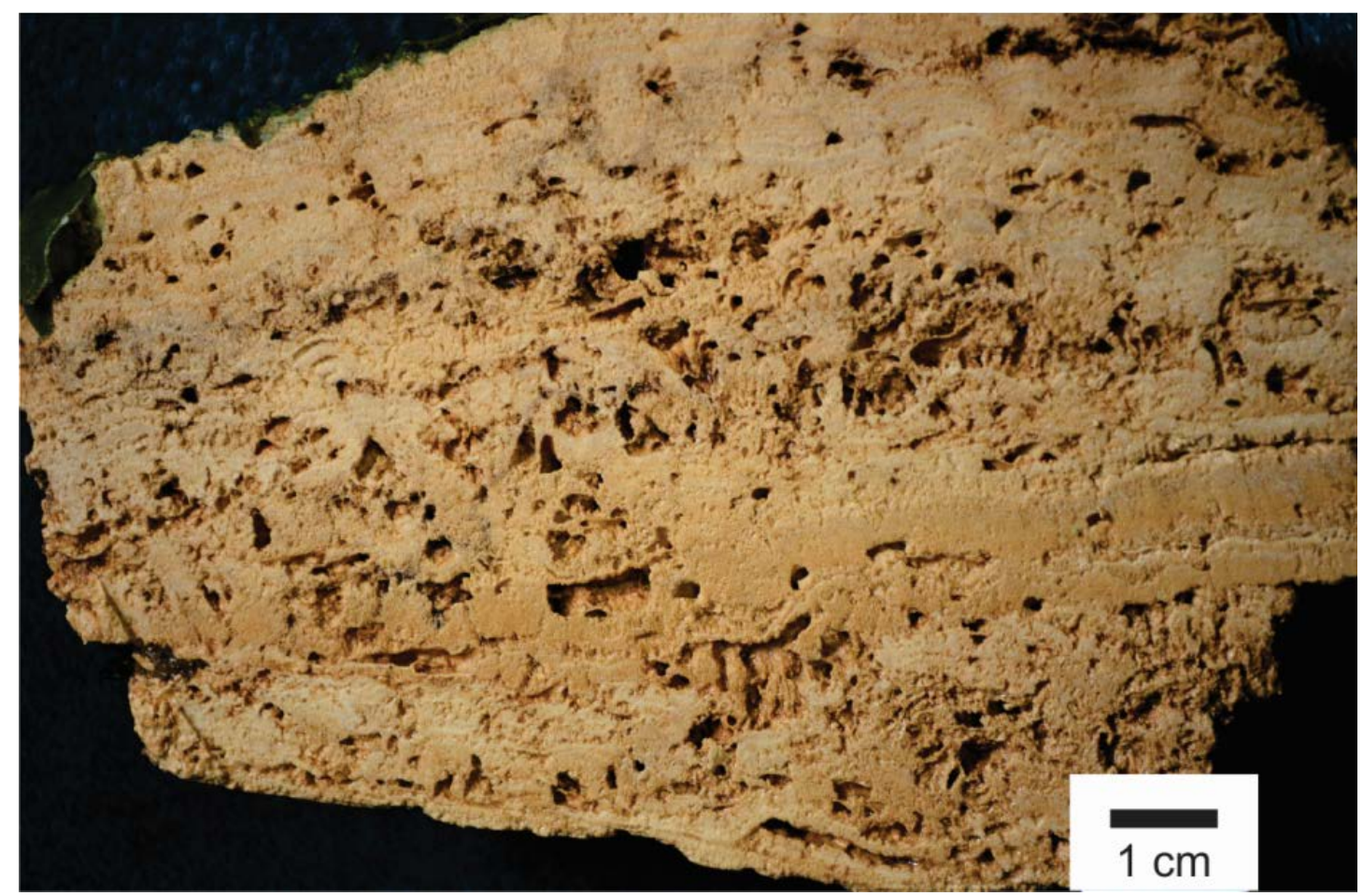

Figura 11 - Corte de amostra de tufa ativa no afluente do Rio Catas Altas, depósito 2.

\section{DISCUSSÕES}

As novas ocorrências de tufas estão associadas a bacias de drenagem com predominância de recarga autogênica, com $71 \%$ no Córrego Bombas-Taquaruvira e $87 \%$ no Rio Catas Altas, o que gera águas limpas e com altos teores de carbonato de cálcio dissolvido. Rios alogênicos fornecem águas mais corrosivas e ricas em sedimentos terrígenos em suspensão. Estas características fisiográficas regionais e de predomínio de recarga autogênica também são observadas na região da Serra do André Lopes onde tufas são comuns (Sallun et al. 2012). 

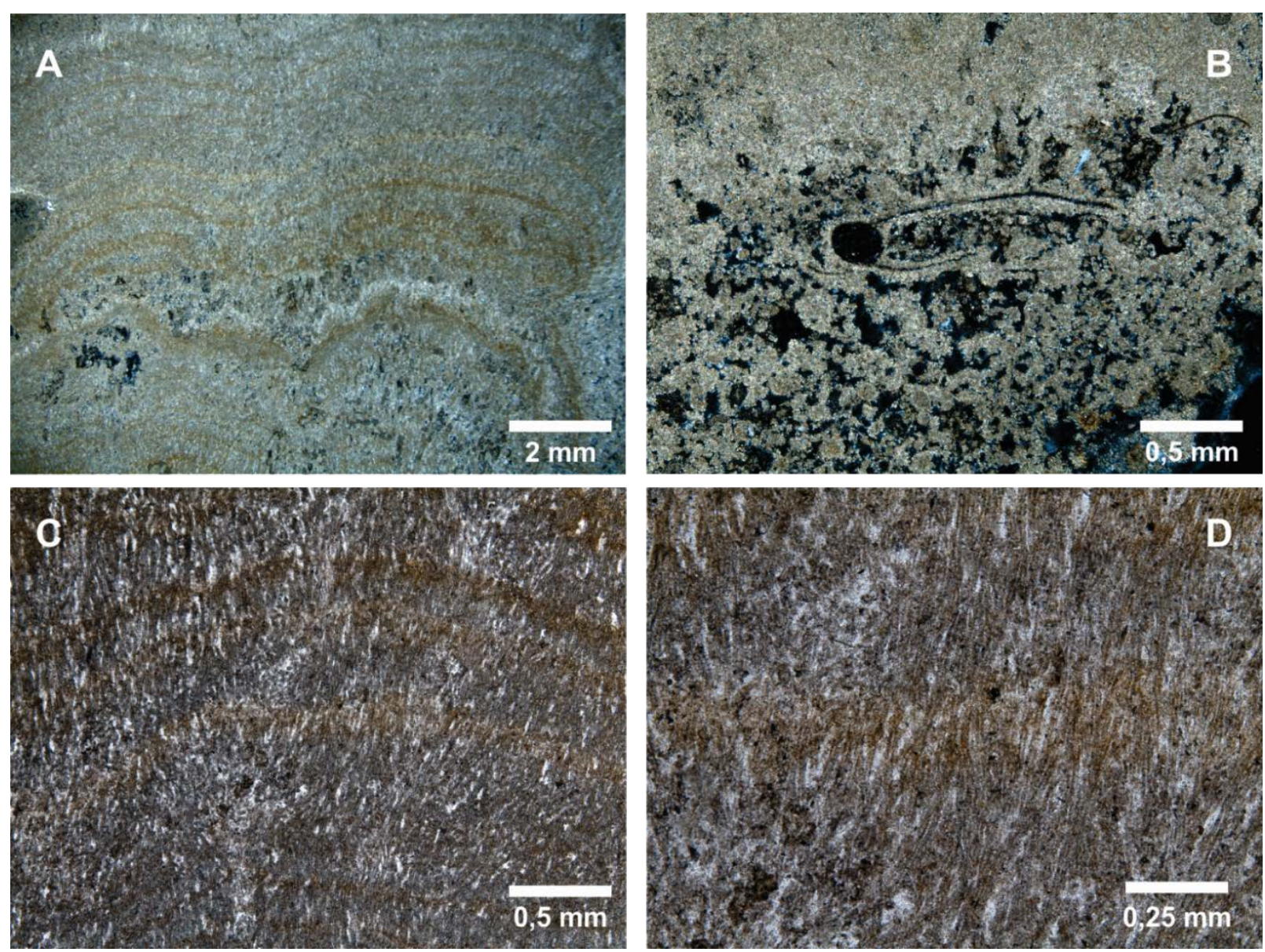

Figura 12 - Fotomicrografias do depósito ativo do afluente do Rio Catas Altas (depósito 2): A- Laminação ondulada caracterizada por alternância de lâminas claras e um pouco mais escuras; B- Moldes de vegetais; C- Filamentos de possíveis cianobactérias, perpendiculares à laminação; D- Detalhe de C. Polarizadores cruzados em A e B e descruzados em C e D.

As condições climáticas e ambientais locais, de clima úmido e vegetação de Mata Atlântica, são favoráveis à deposição de tufa. Árvores caídas na drenagem e raízes expostas ao longo do canal desempenham um papel significativo na deposição de tufa, aumentando localmente a turbulência do fluxo de água e consequentemente a saída de $\mathrm{CO}_{2}$ e ocasionalmente bloqueiam detritos (material vegetal ou sedimentos clásticos) e criam condições favoráveis para o crescimento inicial das represas ou cachoeiras de tufa.

O depósito do Córrego Bombas está inativo, o que se deve provavelmente à menor porcentagem de recarga autogênica em relação ao afluente do rio Catas Altas, onde ocorre um depósito ativo. Em relação aos depósitos do afluente do rio Catas Altas, a deposição ativa se encontra na porção da drenagem onde a recarga é totalmente autogênica.

Os depósitos mais significativos são em cachoeiras, com paredes bastantes inclinadas a verticais, sugerindo controle físico-químico- biológicos para a deposição de tufa nestes locais. Há deposição em porções de alto gradiente hidráulico e fluxo turbulento de água (cachoeiras), condicionados pela desgaseificação do $\mathrm{CO}_{2}$ em águas supersaturadas em carbonato. Contudo as feições estromatolíticas e os filamentos de bactérias encontrados evidenciam contribuição biológica na deposição de carbonato. Filamentos de bactérias foram observados no depósito do Córrego do Taquaruvira e no depósito Afluente do Rio Catas Altas, e microbialitos foram observadas em todas as amostras, o que indica contribuição biogênica importante na formação dos depósitos. Nos locais de maior energia, a maior colonização de cianobactérias é possível devido à ausência de organismos predadores. As tufas em cachoeira que estão nas encostas íngremes no afluente do Rio Catas Altas (depósito 2) são as que exibem morfologia mais típica, maiores espessura e cobertura.

O gradiente hidráulico na porção da drenagem onde se localiza o depósito do 
Córrego do Taquaruvira é relativamente baixo em relação a outras porções da mesma drenagem, sendo provável a ocorrência de depósitos de tufas a montante (não visitado). No depósito Afluente do Rio Catas Altas o gradiente de toda a drenagem é mais alto, contudo os depósitos inativos (depósito 1) observados se localizam em setores com menor gradiente hidráulico.

O depósito 1 no afluente do Rio Catas Altas são matacões de ruditos cimentados que não estão in situ e sendo atualmente erodidos. Trechos de tufas erodidas, mesmo as encontradas em canais de drenagem que tem deposição ativa, surgem como resultado de mudanças na taxa de fluxo do rio (mudanças nas quantidades de precipitação) ou, mais provavelmente, mudanças na posição e morfologia do canal do rio, num ciclo contínuo de deposição e erosão. A alta solubilidade da tufa favorece a dissolução, especialmente durante os períodos de não-deposição, e uma grande parte da deposição atual de tufas pode ser resultado da precipitação de carbonatos originados da dissolução de tufas antigas.

Se todo o leito da drenagem apresenta apenas tufas erodidas, como parece ser a situação no Córrego Taquaruvira, pode ser devido a um aumento da contribuição de recarga alogênica, relacionado ao próprio desenvolvimento da bacia, que com a erosão remontante dos rios, atingem rochas não carbonáticas tornando as águas mais ácidas e com maior teor de sedimentos siliclásticos em suspensão.

Alguns depósitos, que apresentam estruturas laminadas e formas estromatolíticas arredondadas, são depósitos autóctones. Depósitos deste tipo foram observados em ambas as ocorrências estudadas. A complexidade da laminação interna mostra um ambiente de alta turbulência. Tanto a forma externa, quanto a laminação interna acompanha o relevo local, seja de rochas do embasamento, seja de antigos depósitos de tufa. As tufas são compostas predominantemente por micrita, que varia entre tonalidades de bege claro e escuro, com microesparito primário ocorrendo de maneira muito restrita, contudo comumente há microesparito secundário preenchendo poros, total e parcialmente, por vezes formando drusas. Também são frequentes feições similares a estromatólitos colunares. Foram identificados poros oriundos de moldes de bioclastos, e poros alongados de origem associada ao crescimento bioinduzido da tufa em todas as amostras. Porosidade fenestral só foi identificada nas amostras do depósito do afluente do Rio Catas Altas. Não se observaram ooides e gastrópodes, e sedimentos clásticos foram encontrados apenas em pequenas quantidades.

\section{CONCLUSÕES}

Duas ocorrências inéditas de tufas no Vale do Rio Ribeira foram descritas neste trabalho, que somadas aos depósitos da Serra do André Lopes, representam os únicos depósitos conhecidos no Vale do Ribeira e também os mais meridionais no Brasil e da América do Sul.

As tufas descritas foram classificadas como depósitos de represas e cachoeiras segundo Pedley (1990), depositados em rios de vertente. Também podem ser denominados de barragens e represas autóctones de acordo com Pentecost (2005) ou como um sistema fluvial com cachoeiras segundo Alonso-Zarza \& Tanner (2010).

Podem ser considerados acrescionais e progradantes, com a superposição irregular de camadas e repetições temporais. A classificação morfológica e textural das tufas é bastante complexa, pois ocorre a formação de vários tipos em um mesmo ambiente deposicional (Pentecost, 2005).

A deposição mais intensa de tufa ocorre nos rios e setores onde há alta declividade, dada pela maior perda de $\mathrm{CO}_{2}$ devido à turbulência da água, favorecendo o fator de crescimento tufa. As drenagens que formam as tufas fluem diretamente sobre rochas carbonáticas ou de um planalto de rochas carbonáticas para outras rochas. Essas características geomorfológicas também refletem na morfologia típica dos depósitos como cachoeiras e represas, com variações de acordo com a declividade e a vazão da drenagem.

Os depósitos mais significativos são em cachoeiras, com paredes bastantes inclinadas a verticais, sugerindo controle físico-químico predominante para a deposição de tufa nestes 
locais. Contudo, a presença de feições microbianas em todas as amostras, indica contribuição biogênica importante na formação dos depósitos.

Nas bacias de drenagem estudadas, o amplo predomínio de recarga autogênica, altas concentrações de carbonato de cálcio dissolvido na água e o clima quente e úmido, são os fatores determinantes da deposição de tufa nestes locais.

\section{AGRADECIMENTOS}

Os autores agradecem ao Instituto Geológico pelo apoio e ao CNPq pelas bolsas de Iniciação Científica (B.B. Miraya) e de Produtividade em Pesquisa (W. Sallun Filho e P. C. Boggiani). Agradecimentos também a Vandir de Andrade Junior pelas indicações na Cachoeira do Taquaruvira.

\section{REFERÊNCIAS}

ALMEIDA, F.F.M. Geomorfologia da região de Corumbá. Boletim da associação Associação dos geógrafos Geógrafos Brasileiros, ano III, n. 3, p. 8-18, 1943.

ALMEIDA, F.F.M. Geologia da Serra da Bodoquena (Mato Grosso), Brasil. Boletim da Divisão de Geologia e Mineralogia, DNPM, Rio de Janeiro, v. 219, p. 1-96, 1965.

ALMEIDA, L.H.S. Análise Litofaciológica de Tufas da Serra do Cândido, Município de Itaocara (RJ). Rio de Janeiro, 2016. 115p. Tese (Mestrado em Geologia), Universidade Federal do Rio de Janeiro, PETROBRAS PRH-PB 18.

ALMEIDA, L.H.S. Caracterização geológica e hidrogeológica de tufas da Serra do André Lopes, municípios de Eldorado e Barra do Turvo (SP). São Paulo, 2011. Monografia (Trabalho de Formatura), Instituto de Geociências, Universidade de São Paulo.

ALONSO-ZARZA, A.M. \& TANNER, L.H. (Eds). Carbonates in Continental Settings: Facies, Environments and Processes, Developments in Sedimentology. Amsterdam: Elsevier, 2010.

ALVARES, C.A., STAPE, J.L., SENTELHAS, P.C., GONÇALVES, J.L.M.; SPAROVEK, G. Köppen's climate classification map for Brazil. Meteorologische Zeitschrift, v. 22, n. 6, p. 711-728, 2013.

ARENAS, C.; GUTIÉRREZ, F.; OSÁCAR, C.; SANCHO, C. Sedimentology and geochemistry of fluvio-lacustrine tufa deposits controlled by evaporite solution subsidence in the central Ebro Depression, NE Spain. Sedimentology, v. 47, n. 4, p. 883-909, 2000.

ARENAS-ABAD, C.; VÁZQUEZ-URBEZ, M.; PARDOTIRAPU, G.; SANCHO-MARCÉN, C. Fluvial and Associated Carbonate deposits. In: Alonso-Zarza, A.M. \& Tanner, L.H. (Ed.) Carbonates in Continental Settings: Facies, Environments and Process. Developments in Sedimentology, v. 61, p. 133-175. Amsterdam: Elsevier, 2010.

AULER, A.S. Karst Evolution and Palaeoclimate in Eastern Brazil. Bristol, 1999. Tese (Doutorado), University of Bristol.

AULER, A.S. \& SMART, P.L. Late Quaternary paleoclimate in semiarid northeastern Brazil from $U$ Series dating of travertine and water-table speleothems. Quaternary Research, v. 55, p. 159-167, 2001.

AULER, A.S., WANG, X., EDWARDS, R.L., CHENG, H., CRISTALLI, P.S., SMART, P.L., RICHARDS, D.A. Quaternary ecological and geomorphic changes associated with rainfall events in presently semi-arid northeastern Brazil. Journal of Quaternary Science, v. 19, n. 7, p. 693-701, 2004.

BOGGIANI, P.C.; COIMBRA, A.M.; GESICKI, A.L.D.; SIAL, A.N.; FERREIRA, V.P.; RIBEIRO, F.B.; FLEXOR, J.M. Tufas Calcárias da Serra da Bodoquena, MS: cachoeiras petrificadas ao longo dos rios. In: SCHOBBENHAUS, C.; CAMPOS, D.A.; QUEIROZ, E.T.; WINGE, M.; BERBERTBORN, M. (Eds) Sítios Geológicos e Paleontológicos do Brasil. Brasília-DF, DNPM, p. 249-259, 2002.

CAMPANHA, G.A.C. O papel do sistema de zonas de cisalhamento transcorrentes na configuração da porção meridional da Faixa Ribeira. São Paulo, 2002. 138p. Tese (Livre-Docência), Instituto de Geociências, Universidade de São Paulo.

CAMPANHA, G.A.C.; BASEI, M.A.S.; TASSINARI, C.; NUTMAN, AP; FALEIROS, F.M. Constraining the age of Iporanga Formation with SHRIMP U-Pb zircon: implications for possible Ediacaran glaciation in the Ribeira Belt, SE Brazil. Gondwana Research, v. 13, p. 117-125, 2008.

CARTHEW, K.D.; TAYLOR, M.P.; DRYSDALE, R.N. Are current models of tufa sedimentary environments applicable to tropical systems? A case study from Gregory River. Sedimentary Geology, v. 162, n. 3, p. 199-218, 2003.

CORRÊA, D. Caracterização, cronologia e gênese das tufas da Serra das Araras - Mato Grosso. Belo Horizonte, 2006. 79 p. Dissertação (Mestrado), Departamento de Geografia, Universidade Federal de Minas Gerais.

CORRÊA, D. \& AULER, A.S. Tufas calcárias da Serra das Araras (MT): Um notável depósito sedimentar Quaternário. In: ENCONTRO BRASILEIRO DE ESTUDOS DO CARSTE, II, 2007, São Paulo. Resumos Expandidos e Simples...São Paulo, p. 11.

CORRÊA, D.; AULER, A.; WANG, X.; EDWARDS, R.L.; CHENG, H. Geomorphology and genesis of the remardkable Araras Ridge tufa deposit, Western Brasil. Geomorphology, v. 134, n. 1-2, p. 94-101, 2011.

CRISTALLI, P.S. Macrofitofósseis em tufos calcários quaternários do norte da Bahia como indicadores paleoclimáticos. São Paulo, 2006. 195p. Tese (Doutorado em Geociências), Instituto de Geociências, Universidade de São Paulo.

DUARTE, L. \& VASCONCELOS, M.E.C. Vegetais do Quaternário do Brasil. I- Flórula de Russas, CE. Anais da Academia Brasileira de Ciências, v. 52, n. 1, p. 37-48, 1980a.

DUARTE, L. \& VASCONCELOS, M.E.C. Vegetais do Quaternário do Brasil. I- Flórula de Umbuzeiro, PB, CE. Anais da Academia Brasileira de Ciências, v. 52, n. 1, p. 93-180, 1980b.

FALEIROS, F.M. Evolução de terrenos tectonometamórficos da Serrania do Ribeira e Planalto Alto Turvo (SP, PR). São Paulo, 2008. 318p. Tese (Doutorado) Instituto de Geociências São Paulo, Universidade de São Paulo.

FALEIROS, F.M., MORAIS, S.M., COSTA, V.S. Geologia e Recursos Minerais da Folha Apiaí - SG.22-X-B-V Estados de São Paulo e Paraná, escala 1:100.000, 1. (Ed) v. 1. Programa Geologia do Brasil, CPRM-Serviço Geológico do Brasil, São Paulo, p. 107, 2012.

FLÜGEL, E. Microfacies of carbonate rocks: analysis, interpretation and application. New York: Springer. 976p. 2004.

FORD, D.C. \& WILLIAMS, P.W. Karst Geomorphology and Hydrology. Londres: Unwin. 601p. 1989. 
FORD, T.D. \& PEDLEY, H.M. A review of tufa and travertine deposits of the world. Earth Science Reviews, v. 41, p. 117175, 1996.

FREYTET, P. \& VERRECCHIA, E.P. Freshwater organisms that build stromatolites: a synopsis of biocrystallization by prokaryotic and eukaryotic algae. Sedimentology, v. 45, p. 535-563, 1998.

GENTHNER, C.; FERRARI, J.A.; KARMANN, I. Identificação das áreas de recarga de fontes cársticas com o uso do traçador rodamina fwt (área carbonática LajeadoBombas, Iporanga-SP). Revista do Instituto Geológico, São Paulo, v. 24, n. 1/2, p. 11-23, 2003,

GONZALES, Prospecção Geoquímica nas Localidades de Vermelho e Morro Preto, Município de Ribeira, SP. In: SIMPÓSIO DE GEOLOGIA, 2, 1979, Rio Claro. Resumos Expandidos...Rio Claro: SBG, v. 2.

GRADZIŃSKI, M. Factors controlling growth of modern tufa: results of a field experiment. In: Pedley, P.M., Rogerson, M. (Eds.), Tufas and Speleothems: Unravelling the Microbial and Physical Controls. Geological Society, London, Special Publication, v. 336, p. 143-191, 2010.

HARDIE, L.A. Sedimentation on the modem tidal flats of Northwest Andros Island. - John Opkins University Studies in Geology, v. 22, p. 202, 1977.

KARMANN, I. \& FERRARI, J.A. Carste e cavernas do Parque Estadual Turístico do Alto Ribeira (PETAR), SP. In: SCHOBBENHAUS, C.; CAMPOS, D.A.; QUEIROZ, E.T.; WINGE, M.; BERBERT-BORN, M.L.C. (Eds.). Sítios geológicos e paleontológicos do Brasil. p. 401-413. 2002

KARMANN, I. \& SANCHEZ, L.E. Distribuição das rochas carbonáticas e províncias espeleológicas do Brasil. EspeleoTema, n. 13, p. 105-167, 1979.

KARMANN, I. \& SANCHEZ, L.E. Speleological Provinces in Brazil. In: CONGRESO INTERNACIONAL DE ESPELEOLOGIA, IX, Barcelona, 1986. Anais... Barcelona, v. 1, p. 151-153.

KARMANN, I. Evolução e dinâmica atual do sistema cárstico do alto Vale do rio Ribeira de Iguape, sudeste do estado de São Paulo. São Paulo, 1994. 241p. Tese (Doutorado em Geociências) - Instituto de Geociências, Universidade de São Paulo São Paulo.

OLIVEIRA, E.C., 2009. Tufas Calcárias da Serra da Bodoquena, MS. São Paulo, 2009. 147p. Dissertação (Mestrado), Instituto de Geociências, Universidade de São Paulo.

PEDLEY, H.M. Classification and environmental models of cool freshwater tufas. Sedimentary Geology, v. 68, p. 143154, 1990.

PENTECOST, A. Travertine. Londres: Springer. 445pp. 2005. RAMOS, R.R.C.; BRAGA, M.V.C.; OZANICK, C.; JATOBA, L.O.; CASTRO, J.W.A. Primeiro registro de tufas calcárias no Estado do Rio de Janeiro. In: CONGRESSO DA ASSOCIAÇÃO BRASILEIRA DE ESTUDOS DO QUATERNÁRIO, X, 2005, Guarapari. Atas...Guarapari: SBG.
REYES, Y.A. Caracterização da geometria de depósitos sedimentares na borda sudoeste da Bacia Potiguar. Natal, 2003. 75p. Dissertação (Mestrado) - Centro de Ciências Exatas e da Terra, Universidade Federal do Rio Grande do Norte.

REYES, Y.A.; BEZERRA, F.H.R.; LIMA FILHO, F.P. Falhas de gravidade em tufas calcários na Bacia Potiguar, NE do Brasil. In: SIMPÓSIO NACIONAL DE ESTUDOS TECTÔNICOS, 9, 2003, Armação de Búzios. Resumos... Armação de Búzios: SBG.

ROSS, J.L.S. \& MOROZ, I.C. Mapa Geomorfológico do Estado de São Paulo - escala 1:500.000 - FFLCH-USP-IPTFAPESP- São Paulo. 1997.

SALLUN FILHO, W. \& KARMANN, I. Geomorphological map of the Serra da Bodoquena karst, west-central Brazil. Journal of maps, v 3, n. 1, p. 282-295, 2007.

SALLUN FILHO, W. Geomorfologia e geoespeleologia do carste da Serra da Bodoquena, MS. São Paulo, 2005, 196p. Tese (Doutorado em Geociências), Instituto de Geociências, Universidade de São Paulo.

SALLUN FILHO, W.; ALMEIDA, L.H.S.; BOGGIANI, P.C.; KARMANN, I. Characterization of quaternary tufas in the Serra do André Lopes karst, southeastern Brazil. Carbonates and Evaporites, v. 27, n. 41367, supl. 4, p. 357-373, 2012.

SALLUN FILHO, W.; KARMANN, I.; BOGGIANI, P.C.; PETRI, S.; CRISTALLI, P.S.; UTIDA, G. A deposição de tufas quaternárias no estado de Mato Grosso do Sul: proposta de definição da formação Serra da Bodoquena. Geologia USP, Série Científica. Série Científica, v. 9.3, p. 47-60, 2009.

SIGA JUNIOR, O.; BASEI, M.A.S.; SATO, K.; PASSARELLI, C.R.; NUTMAN, A.; MCREATH, I.; PRAZERES FILHO, H.J. Calymmian (1.50 1.45 Ga) magmatic records in Votuverava and Perau sequences, south-southeastern Brazil: Zircon ages and $\mathrm{Nd} \mathrm{Sr}$ isotopic geochemistry. Journal of South American Earth Sciences, v. 32, p. 301-308, 2011.

SOUZA-LIMA, W. \& FARIAS, R.M. A flora quaternária dos travertinos de Itabaiana, Sergipe. In: PALEO 2007, Sergipe, Resumos... Sergipe: p. 7.

TRAVASSOS, L.E.P.; OLIVEIRA, R.I.C. Tufa deposits in the karst region of Montes Claros, Minas Gerais. Acta Carsologica, v. 45, p. 85-96, 2016.

WEBER, W.; JÚNIOR, O.S.; SATO, K.; REIS NETO, J.M.; BASEI, M.A.S.; NUTMAN, A.P. A Formação Água Clara na Região de Araçaíba - SP: Registro U-Pb de Uma Bacia Mesoproterozoica. Geologia USP, Série Científica, v. 4, n. 1, p. 101-110, 2004 